\title{
Detección de levaduras y bacterias ácido lácticas nativas de diferentes cultivares chilenos: Potenciales especies para la producción de vinos reducidos en alcohol
}

\section{Screening native yeast and lactic acid bacteria from different Chilean cultivars: Potential species for production of reduced ethanol wines}

\author{
W. Franco ${ }^{1,4}$, P. Valencia ${ }^{2}$, C. Ramírez ${ }^{2}$, y A. Urtubia ${ }^{2,3}$ \\ ${ }^{1}$ Pontificia Universidad Católica de Chile, Departamento de Ingeniería Química y Bioprocesos. Av. Vicuña Mackena, 4860 \\ Santiago, Chile \\ ${ }^{2}$ Universidad Técnica Federico Santa María, Departamento de Ingeniería Química y Ambiental. Av. España, 1680 Valparaíso, Chile \\ ${ }^{3}$ Centro Regional de Estudios en Alimentación Saludable. Av. Universidad 330, Curauma, Valparaíso, Chile \\ ${ }^{4}$ Pontificia Universidad Católica de Chile, Departamento de Ciencias de la Salud, Carrera de Nutrición. Av. Vicuña Mackena, 4860 \\ Santiago, Chile
}

\begin{abstract}
Resumen. En este estudio se caracterizó la microbiota natural (levaduras y bacterias ácido lácticas) observada durante la fermentación espontánea de variedades de uva de Chile, con el fin de evaluar su potencial para producir vinos con menor contenido de etanol. El potencial de fermentación de las levaduras seleccionadas se determinó en términos de consumo de azúcar y producción de etanol. Las cepas con potencial para producir vinos reducidos en etanol se estudiaron adicionalmente en inoculaciones secuenciales con Saccharomyces cerevisiae. Se identificaron nueve especies no Saccharomyces y solo tres géneros de bacterias ácido lácticas. Durante las etapas finales de fermentación, S. cerevisiae y L. mesenteroides fueron dominantes, mientras que solo Candida, Metchnikowia, Torulaspora y Lachancea spp. se observaron después de 14 días de fermentación. La fermentación de cultivo puro con cepas aisladas seleccionadas mostró aproximadamente un 50\% de utilización de azúcar, con una producción de etanol que varió desde 6.25 a $9.25 \%$ v/v. Nuestros resultados sugieren que las levaduras nativas $R$. glutinis, M. pulcherrima y H. uvarum, aisladas en este estudio, son potenciales para producir vinos reducido en etanol. Sin embargo, se necesitan más estudios sobre la contribución en sabor y el aroma.
\end{abstract}

\begin{abstract}
The potential use of non-traditional yeast species opens new possibilities regarding wine flavor, aroma, texture and ethanol content. Low and reduced ethanol wines have attracted much interest, and research has led to novel techniques to reduce ethanol content, including the use of non-traditional yeast. The aim of this study was to characterize the natural microbiota (yeasts and lactic acid bacteria) observed during spontaneous fermentation of six grape varieties from the Maule Region (Chile). Thus, the fermentative potential of selected yeast isolates was determined in terms of sugar consumption and ethanol production. Isolates with potential for producing reduced ethanol wines were further studied in sequential inoculations with Saccharomyces cerevisiae. Nine non-Saccharomyces species belonging to seven genera were identified from the spontaneous fermentation, but only three lactic acid bacteria genera were identified. During final fermentation stages, S. cerevisiae and L. mesenteroides were dominant, while only Candida, Metchnikowia, Torulaspora, and Lachancea spp. were observed after 14 days of fermentation. Pure culture fermentation with selected isolates showed about 50\% sugar utilization, with ethanol production ranging from 6.25 to $9.25 \% \mathrm{v} / \mathrm{v}$. Regarding sequential inoculations, less than $2 \%$ of sugars remained after 10 days of fermentation, and significantly less ethanol was produced than in control samples. Our results suggest that native yeasts R. glutinis, M. pulcherrima and H. uvarum, isolated in this study, potentially serve to produce reduced ethanol wines. However, more studies on flavor and aroma contribution are needed.
\end{abstract}

\section{Introducción}

La fermentación del vino es un sistema microbiano complejo que implica el desarrollo secuencial de varias especies de microorganismos, los cuales durante el proceso de fermentación determinan la calidad del vino y sus atributos específicos. La presencia de microbiota nativa define características y perfiles de vino únicos [1], incluida la producción de vinos con bajo contenido de etanol [2-4]. En los últimos años, la demanda de los consumidores 
se han desplazado hacia los vinos con menor contenido de alcohol. Esto como consecuencia de hábitos más saludables y políticas públicas con respecto al consumo de alcohol [5]. Las técnicas industriales actuales para la reducción del contenido de alcohol en los vinos se basan en enfoques de pre-fermentación o en la separación de la molécula después de la fermentación [5]. Y dependiendo del contenido de alcohol resultante, el vino se clasifica como vino de bajo contenido de alcohol (menos de $1 \%$ v/v) o vino de contenido alcohólico reducido (3 a $9 \%$ $\mathrm{v} / \mathrm{v})$. Alternativamente, el control de la producción de etanol durante el proceso de fermentación ha adquirido recientemente más importancia y en la actualidad, el uso de levaduras no tradicionales ha ganado mucho interés para este propósito [6,7]. Diversas colecciones de levaduras no Saccharomyces han sido caracterizadas en cuanto a perfiles fermentativos. Especies como Metschnikowia pulcherrima, Kluyveromyces spp., Torulaspora delbrueckii AWRI1152, y Zygosscharomyces bailii AWRI1578 han sido reportadas como candidatas potenciales para producir vinos reducidos en etanol [2,8]. Una estrategia que acompaña el uso de levaduras no tradicionales, es el de la inoculación secuencial, que ha resultado en mostos fermentados con menos alcohol y con diferentes perfiles sensoriales [4,8-12]. La inoculación secuencial garantiza la utilización de glucosa y, por lo tanto, la estabilidad del vino, aunque también se han informado algunos atributos volátiles que podrían afectar negativamente el aroma del vino [4].

Las levaduras no Saccharomyces están comúnmente presentes en las bayas de uva maduras y en el mosto fresco como parte de la microflora nativa junto con bacterias del ácido láctico (BAL) y otros microorganismos [7,13]. Aunque estas levaduras nativas son menos competitivas que $S$. cerevisiae, juegan un papel significativo durante las primeras etapas de fermentación, puesto que pueden influir en las características del vino resultante, al producir enzimas extracelulares y por lo tanto modificar sus propiedades sensoriales y organolépticas $[4,14,15]$.

Dado el potencial de las levaduras no tradicional para producir metabolitos deseables y vinos de bajo y/o reducido contenido de alcohol, esta investigación tiene como objetivo caracterizar las levaduras nativas y BAL presentes en diferentes uvas chilenas, comúnmente utilizadas para la producción regional de vino; caracterizar el perfil fermentativo de aislados seleccionados en fermentaciones de laboratorio, y estudiar la capacidad de las cepas aisladas para producir mosto fermentado reducido en etanol en fermentación secuencial con $S$. cerevisiae.

\section{Materiales y Métodos}

\subsection{Muestras de uvas}

Bayas de uva (Syrah, Merlot, Pinot, Carignan, Cabernet Sauvignon y Chardonnay) fueron recolectadas en la Región del Maule (Chile) durante la temporada de vendimia del año 2015. Las muestras se recolectaron por triplicado, se almacenaron en bolsas ziplock y se transportaron refrigeradas al Laboratorio de Microbiología de Alimentos de la Pontificia Universidad Católica de Chile (Santiago, Chile). A su llegada, las muestras se usaron inmediatamente para la experimentación.

\subsection{Fermentaciones}

Después de separar manualmente las uvas de los tallos y hojas, estas fueron cuidadosamente trituradas y procesadas hasta obtener el jugo. Cuatrocientos mililitros de jugo de uva fueron trasvasados, por triplicado a matraces Erlenmeyer estériles de $500 \mathrm{ml}$ provistos de tapas y airlocks. Los matraces se incubaron a 25 y $30^{\circ} \mathrm{C}$, para levaduras y BAL, respectivamente, con agitación de $100 \mathrm{rpm}$ en una incubadora orbital (Stuart, Reino Unido). Se mantuvieron estas condiciones durante 14 días. Diariamente muestras fueron recolectadas para análisis químicos y caracterización microbiológica.

\subsubsection{Caracterización microbiológica}

Las muestras recolectadas fueron diluidas serialmente en agua de peptona al $0.01 \%$ y se sembraron en placas. La cuantificación de levaduras se realizó usando extracto de levadura Cloranfenicol Glucosa Agar (YGC agar, Merk, Alemania) y Wallerstein Laboratory Nutrient agar (WLN agar, Oxoid, Inglaterra). y agar de levadura y moho (agar YMA, Oxoid, Inglaterra). Los medios de cultivo fueron suplementados con difenil $(500 \mathrm{mg} / \mathrm{ml})$ para evitar el crecimiento de mohos [16]. Las placas se incubaron aeróbicamente a $25^{\circ} \mathrm{C}$ durante al menos $48 \mathrm{~h}$ o hasta que se observaron colonias en las placas. Para las BAL, se utilizó agar de Man, Rogosa y Sharpe (agar MRS, Oxoid, Inglaterra) complementado con $1 \%$ de cicloheximida (solución al $0.1 \%$, Oxoid) para inhibir el crecimiento de levaduras y mohos. Las placas de agar MRS se incubaron anaeróbicamente usando cabinas de aneroobiosos suplementadas con paquetes de Gas (Oxoid) a $30^{\circ} \mathrm{C}$ durante $48 \mathrm{~h}$.

\subsubsection{Análisis químicos}

El pH de las muestras se controló usando un medidor de pH (Hannah Instruments, Rumania). La concentración de ácidos orgánicos, azúcares y etanol se midió mediante cromatografía líquida de alta resolución (HPLC) usando una columna de intercambio de aniones Amimez HPX/87H (Bio / Rad Laboratories, Hecules, CA) para la separación de componentes. La temperatura de la columna se mantuvo a $55^{\circ} \mathrm{C}$, y los componentes de la muestra se eluyeron con ácido sulfúrico $5 \mathrm{mM}$ a un flujo de $0.5 \mathrm{ml} / \mathrm{min}$. Se utilizó un detector de arreglo de diodos LaChrom L-7450A (Hitachi, Japón) establecido a $210 \mathrm{~nm}$ para cuantificar los ácidos orgánicos y un detector de índice de refracción LaChrom L-7490 (Hitachi, Japón) conectado en serie para medir glucosa, fructosa, etanol y glicerol.

\subsection{Aislamiento e identificación de microorganismos}

Las colonias observadas visualmente en las placas de agar se caracterizaron en términos de morfología [16]. Se recogieron tres a cuatro clones independientes de aislados representativos de cada tipo de morfología y se sembraron por estrías en el medio de cultivo respectivo. Se prepararon cultivos stock en caldo MRS y YM según corresponda, suplementado con de glicerol (SigmaAldrich). Las levaduras y bacterias asiladas se caracterizaron primero por su perfil bioquímico. Para esto, se usaron tiras API 
Tabla 1. Total yeast and bacterial counts Oog CFU/mL) determined during the spontaneous fermentation of Chilean grape berries.

\begin{tabular}{|c|c|c|c|c|c|c|}
\hline \multirow{3}{*}{ Grape variety } & \multicolumn{2}{|c|}{ Yeast } & \multicolumn{2}{|c|}{ LAB } & \multicolumn{2}{|c|}{ pH } \\
\hline & \multicolumn{4}{|c|}{$\log \mathrm{CFU} / \mathrm{mL}$} & & \\
\hline & Day 0 & Day 14 & Day 0 & Dav 14 & Day 0 & Day 14 \\
\hline $\begin{array}{l}\text { Cabernet } \\
\text { Sauvignon }\end{array}$ & $2.81 \pm 0.07 \mathrm{~A}$ & $6.39 \pm 0.12 \mathrm{~A}$ & $2.13 \pm 0.26 \mathrm{~A}$ & $5.40 \pm 0.11 \mathrm{~A}$ & $3.67 \pm 0.01 \mathrm{~A}$ & $3.68 \pm 0.04 \mathrm{~A}$ \\
\hline Chardonnay & $3.08 \pm 0.00 \mathrm{~A}$ & $6.17 \pm 0.02 \mathrm{~B}$ & $2.38 \pm 0.90 \mathrm{~B}$ & $5.55 \pm 0.006 \mathrm{~A}$ & $3.60 \pm 0.00 \mathrm{~B}$ & $3.55 \pm 0.00 \mathrm{~B}$ \\
\hline Carignan & $2.69 \pm 0.08 \mathrm{~B}$ & $6.57 \pm 0.09 \mathrm{C}$ & $1.72 \pm 0.05 \mathrm{C}$ & $5.60 \pm 0.17 \mathrm{~A}$ & $3.50 \pm 0.03 \mathrm{~B}$ & $3.52 \pm 0.04 \mathrm{~B}$ \\
\hline Merlot & $3.19 \pm 0.03 \mathrm{C}$ & $6.23 \pm 0.10 \mathrm{~B}$ & $1.81 \pm 0.08 \mathrm{C}$ & $5.61 \pm 0.04 \mathrm{~A}$ & $3.58 \pm 0.01 \mathrm{~B}$ & $3.55 \pm 0.02 \mathrm{~B}$ \\
\hline Pinot & $3.36 \pm 0.03 \mathrm{D}$ & $6.86 \pm 0.37 \mathrm{D}$ & $1.69 \pm 0.08 \mathrm{C}$ & $4.61 \pm 0.04 \mathrm{~B}$ & $3.43 \pm 0.00 \mathrm{C}$ & $3.59 \pm 0.00 \mathrm{~B}$ \\
\hline Syrah & $2.89 \pm 0.14 \mathrm{~A}$ & $6.24 \pm 0.56 \mathrm{~B}$ & $1.82 \pm 0.17 \mathrm{C}$ & $5.08 \pm 0.01 \mathrm{C}$ & $3.47 \pm 0.01 \mathrm{C}$ & $3.26 \pm 0.01 \mathrm{C}$ \\
\hline
\end{tabular}

Yeast population correspond to counts $\mathrm{m}$ WLN agar. Lactic acid bacteria (LAB) population correspond to counts $\mathrm{m}$ MRS agar. Values represent the average \pm standard deviation of two trials conducted in triplicated. Different letters within columns represent significant differences $(\alpha=0.05)$

(BioMériux, EE. UU.) Siguiendo las instrucciones del fabricante. Se usaron el medio ID $32 \mathrm{C}$ y CHL para bacterias de levadura y ácido láctico, respectivamente. Una vez que los aislamientos se clasificaron como pertenecientes a las familias de levaduras o BAL, se identificaron utilizando la secuenciación parcial del gen del ARNr 26S o $16 \mathrm{~S}$, respectivamente. Se obtuvo ADN cromosómico bacteriano y de levadura usando el kit de extracción y purificación de ADN genómico GeneJET (Thermo Scientific, n. ${ }^{\circ}$ K0722, Lituania).

\subsection{Perfil fermentativo de levaduras no Saccharomyces}

Cepas de levaduras no tradicionales aisladas en los pasos anteriores fueron seleccionadas para determinar el perfil fermentativo en cultivo solo en jugo de uva, Mosto de uva Carmenere (Región de Valparaíso, Chile) fue esterilizado mediante filtración (2 um, Nalgene). Los mostos filtrados fueron nitrogenados con fosfato amónico dibásico (DAP, J.T.) El mosto estandarizado se colocó en frascos estériles de $500 \mathrm{ml}$ provistos con tapas y airlocks. Cultivos puros fueron inoculados a una concentración de aproximadamente $10^{8} \mathrm{UFC} / \mathrm{ml}$. Los matraces se incubaron y se caracterizaron como se describe en 2.2 durante 8 días.

\subsection{Inoculaciones secuenciales con levaduras nativas seleccionadas}

Los aislados que mostraron potencial para la fermentación del mosto y resultaron en un menor contenido de alcohol, fueron seleccionados para inoculaciones secuenciales. El mosto estandarizado (como se describe en 2.3) se colocó en recipientes de fermentación de vidrio de 41 , con agitación, temperatura y control automático de $\mathrm{pH}$ (YT Ingeniería, Valparaíso, Chile). Los fermentadores se inocularon con cada uno de los cultivos de levadura seleccionados con aproximadamente $10^{8} \mathrm{UFC} / \mathrm{ml}$. Cuando 60 a $65 \%$ de azúcares fueron consumidos, se añadió un inóculo de $S$. cerevisiae $\left(10^{8} \mathrm{UFC} / \mathrm{ml}\right)$ para permitir el consumo total de azúcar. Los experimentos se mantuvieron en estas condiciones durante 8 días. Los experimentos control siguieron el mismo diseño experimental, pero se inocularon solo con cultivo iniciador de $S$. cerevisiae a la misma concentración. Durante el proceso de fermentación, se monitoreó el pH con un medidor de pH portátil 220 (sistema de Innovación HILAB,
Joao de Madera, Portugal), se midió la acidez total (como ácido tartárico) y nitrógeno usando una Unidad de Titulación (TitroLine easy, Reino Unido), se midió turbidez con un equipo Turbidity y Bentocheck (Hanna Instruments), y se midió el contenido de sólidos solubles (SSC) mediante Refractómetro ${ }^{\circ}$ Brix Digital (línea Wine, Hanna Instruments), y se determinó la densidad con un picnómetro. Los azúcares y el contenido de alcohol se midieron por HPLC siguiendo la metodología mencionada en 2.2.3. Todos los experimentos se llevaron a cabo por duplicado y se probaron tres réplicas de cada muestra.

\subsection{Análisis estadístico}

Se analizaron los recuentos de placas microbianas, las concentraciones medidas de ácidos orgánicos, azúcares y etanol, así como los otros parámetros de fermentación, utilizando el procedimiento de análisis de varianza (ANOVA) con la prueba de rango múltiple de Duncan con el software Statistical Analysis Systems versión 9.0 (SAS Institute, Cary, NC).

\section{Resultados y discusión}

\subsection{Caracterización microbiana de fermentación espontánea}

Se procesaron seis variedades diferentes de uva (Región del Maule, Chile) en mosto de uva y se incubaron a 25 y $30^{\circ} \mathrm{C}$. Como era de esperar, una fermentación espontánea se evidenció por cambios químicos y microbiológicos que dieron como resultado mostos fermentados estables después de 14 días de fermentación.

\subsubsection{Caracterización microbiana - Bacterias ácido lácticas}

Para determinar la presencia de BAL, las muestras se colocaron en placas en agar MRS y se incubaron durante $48 \mathrm{~h} 30^{\circ} \mathrm{C}$. El mosto de uva fresco mostró recuentos de BAL cercanos a $2.00 \log \mathrm{CFU} / \mathrm{mL}$ (Tabla 1). A medida que avanzó la fermentación, los recuentos de BAL aumentaron alcanzando valores altos después de 3 días con recuentos finales cercanos a 6.00 log $\mathrm{UFC} / \mathrm{ml}$. Un total de 100 colonias diferentes de BAL se aislaron de placas de agar MRS. Los aislados fueron caracterizados de acuerdo a su morfología, que permitió 
Tabla 2. Changes in metabolites during spontaneous fermentation of 6 types of grape vines.

\begin{tabular}{|c|c|c|c|c|c|c|}
\hline \multicolumn{7}{|c|}{ Sugars and alcohols } \\
\hline \multirow{3}{*}{ Grape variety } & \multirow{2}{*}{\multicolumn{2}{|c|}{$\begin{array}{c}\text { Ethanol } \\
\%(\mathrm{v} / \mathrm{v})\end{array}$}} & \multicolumn{2}{|c|}{$\begin{array}{r}\text { Sugars } \\
\end{array}$} & \multicolumn{2}{|c|}{ Glycerol } \\
\hline & & & \multicolumn{4}{|c|}{$g / L$} \\
\hline & Day 0 & Day 14 & Day 0 & Day 14 & Day 0 & Day 14 \\
\hline Cabernet Sauvignon & $0.00 \pm 0.05 \mathrm{~A}$ & $9.50 \pm 0.04 \mathrm{~A}$ & $300 \pm 2.80 \mathrm{~A}$ & $1.70 \pm 0.05 \mathrm{~A}$ & ND & $1.36 \pm 0.00 \mathrm{~A}$ \\
\hline Chardonnay & $0.00 \pm 0.09 \mathrm{~A}$ & $9.82 \pm 1.17 \mathrm{~A}$ & $325 \pm 4.50 \mathrm{~A}$ & $4.19 \pm 0.68 \mathrm{~B}$ & $0.03 \pm 0.00 \mathrm{~A}$ & $1.17 \pm 0.08 \mathrm{~B}$ \\
\hline Carignan & $0.00 \pm 0.01 \mathrm{~A}$ & $9.923 \pm 0.25 \mathrm{~A}$ & $288 \pm 5.87 \mathrm{~B}$ & $1.18 \pm 0.05 \mathrm{~A}$ & $0.02 \pm 0.00 \mathrm{~A}$ & $1.21 \pm 0.02 \mathrm{~B}$ \\
\hline Merlot & $0.00 \pm 0.05 \mathrm{~A}$ & $7.53 \pm 0.05 \mathrm{~B}$ & $325 \pm 2.35 \mathrm{~A}$ & $2.31 \pm 0.04 \mathrm{C}$ & ND & $0.86 \pm 0.10 \mathrm{C}$ \\
\hline Pinot & $0.00 \pm 0.07 \mathrm{~A}$ & $11.8 \pm 0.88 \mathrm{C}$ & $260 \pm 9.81 \mathrm{~A}$ & $3.12 \pm 0.05 \mathrm{D}$ & $0.04 \pm 0.00 \mathrm{~A}$ & $1.27 \pm 0.06 \mathrm{~A}$ \\
\hline Syrah & $0.00 \pm 0.02 \mathrm{~A}$ & $5.91 \pm 0.43 \mathrm{D}$ & $245 \pm 5.48 \mathrm{C}$ & $7.47 \pm 0.13 \mathrm{E}$ & $0.03 \pm 0.00 \mathrm{~A}$ & $0.82 \pm 0.02 \mathrm{C}$ \\
\hline \multicolumn{7}{|c|}{ Organic acids } \\
\hline \multirow{3}{*}{ Grape variety } & \multicolumn{2}{|c|}{ Lactic acid } & \multirow{2}{*}{\multicolumn{2}{|c|}{$\begin{array}{c}\text { Acetic acid } \\
\text { g/L }\end{array}$}} & \multicolumn{2}{|c|}{ Malic Acid } \\
\hline & & & & 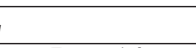 & & \\
\hline & Day 0 & Day 14 & Day 0 & Day 14 & Day 0 & Day 14 \\
\hline Cabernet Sauvignon & ND & ND & ND & $0.07 \pm 0.03 \mathrm{~A}$ & $0.15 \pm 0.00 \mathrm{~A}$ & $0.04 \pm 0.01 \mathrm{~A}$ \\
\hline Chardonnay & ND & $0.12 \pm 0.01 \mathrm{~A}$ & ND & $0.06 \pm 0.02 \mathrm{~A}$ & $0.13 \pm 0.00 \mathrm{~A}$ & $0.08 \pm 0.02 \mathrm{~B}$ \\
\hline Carignan & ND & ND & $0.03 \pm 0.04 \mathrm{~A}$ & $0.10 \pm 0.05 \mathrm{~B}$ & $0.26 \pm 0.02 \mathrm{~B}$ & $0.14 \pm 0.01 \mathrm{C}$ \\
\hline
\end{tabular}

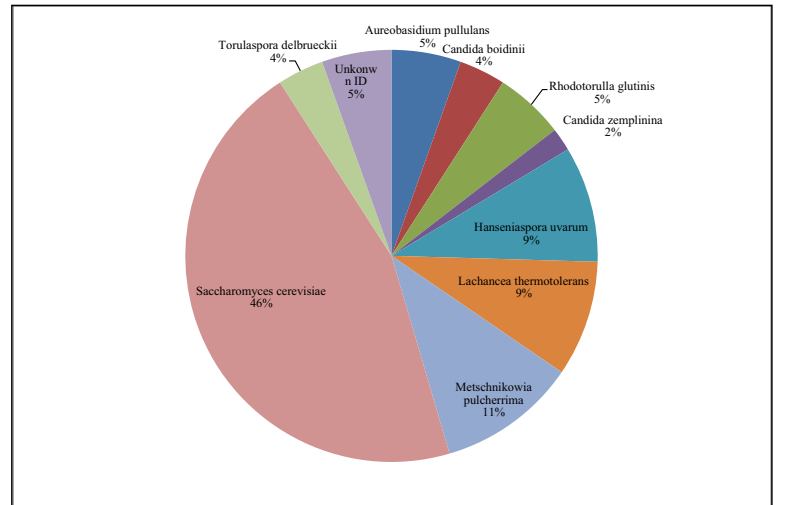

Figure 1. Yeast distribution observed during the spontaneous fermentation of different varieties of Chilean grapevines. Five hundred colonies were isolated, grouped morphologically and identifies by $26 \mathrm{~S}$ RNA.

agruparlos en tres segmentos de características similares y únicas. La identificación molecular, corroboró esta inicial clasificación. Las BAL aisladas pertenecen a las familias Lecuonostoc y Lactobacillus con tres especies identificadas (Tabla 2). Aunque las BAL fueron más diversas en mosto fresco, Leuconostoc mesenteroides ssp. cremoris se observó para las seis uvas al comienzo y al final de la fermentación. Hasta donde sabemos, esta es la primera vez que se reportan BAL en el mosto fresco y durante un proceso de fermentación espontánea para las bayas chilenas.

\subsubsection{Caracterización microbiana - Levadura}

Para la enumeración de levaduras, las muestras se sembraron en diferentes agares incubados a $25^{\circ} \mathrm{C}$ durante $48 \mathrm{~h}$ o hasta que se observaron colonias en placas. Los conteos de levadura de mosto fresco fueron similares para todas las variedades de uva (promedio de $3.00 \log \mathrm{UFC} / \mathrm{ml}$ ). A medida que la fermentación proseguía, la población se incrementó evidenciando un crecimiento exponencial, que alcanzó a recuentos finales superiores a 6,00 log UFC/ml (Tabla 1). En base a las características morfológicas, se aislaron un total de 500 colonias y se identificaron adicionalmente por

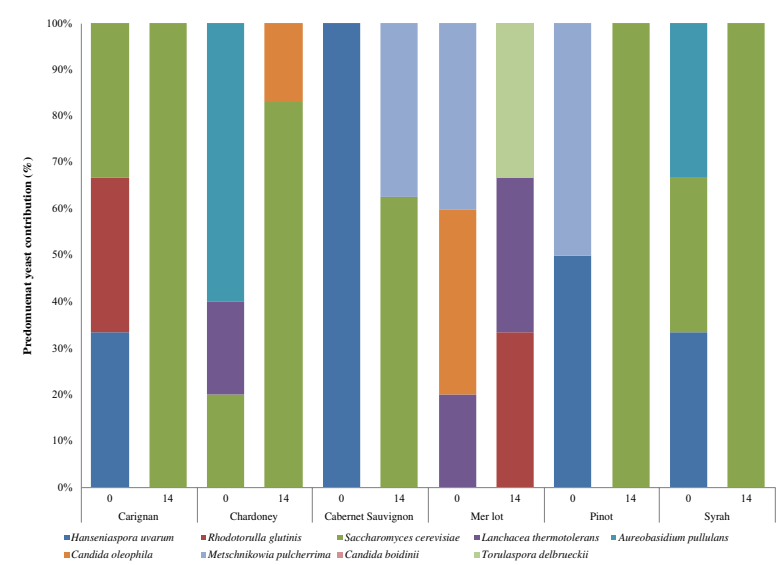

Figure 2. Predominant yeasts isolated in WLN agar at the beginning (day 0 ) and the end (day of the spontaneous laboratory fermentation. Five hundred colonies were isolated, grouped morphologically and identifies by 26 SRNA

DNA cromosómico. Como era de esperar, la mayoría de las levaduras aisladas se identificaron con la especie de Saccharomyces cerevisiae (46\%) (Fig. 1), mientras que la distribución de levaduras no Saccharomyces estuvo compuesta por Metschnikowia pulcherima (11\%), Hanseniaspora uvarum y Lachancea thermotolerans (9\%); Aureobasidium pullulans y Rhodotorula glutinis (5\%); Torulaspora delbrueckii y Candida boidinii (4\%); y Candida zemplinina (2\%) (Fig. 1). El cinco por ciento de los aislamientos no fueron identificados. Aunque, la mayoría de las levaduras no Saccharomyces no se detectaron después de 5 días de fermentación (datos no mostrados), nuestros resultados muestran que tres especies se aislaron después de 14 días (Fig. 2). En Chardonay fermentado, el $16.6 \%$ de las levaduras observdas en este tiempo, fueron identificadas como $R$. glutinis, el $37.5 \%$ de los aislamientos finales de levadura fueron identificados como M. pulcherrima en Cabertent Sauvignon, y en Merlot L. thermotolerans, C. zemplinina y S. cerevisisae se encontraron igualmente distribuidos (33.3\%). Esto sugiere, que existe un stock de levaduras no tradicionales capaces de tolerar las condiciones de estrés del proceso fermentativo. 
Tabla 3. Residual sugar and ethanol produced by different wild yeasts inoculated in sterilized Carmenere must in single culture.

\begin{tabular}{|l|l|l|c|}
\hline Isolate & \% Residual sugars & $\begin{array}{l}\text { Ethanol produced } \\
(\% \mathbf{v} / \mathbf{v})\end{array}$ & $\begin{array}{l}\text { Theoric \% } \\
\text { sugar } \\
\text { transformed in } \\
\text { ethanol }\end{array}$ \\
\hline Lanchacea thermotolerans & $5.91 \pm 0.37 \mathrm{~A}$ & $8.25 \pm 0.50 \mathrm{~A}$ & $29 \%$ \\
\hline Torulaspora delbrueckii & $3.07 \pm 0.07 \mathrm{~B}$ & $9.25 \pm 0.35 \mathrm{~B}$ & $33 \%$ \\
\hline Candida boidinii & $2.99 \pm 0.001 \mathrm{~B}$ & $9.00 \pm 0.02 \mathrm{~B}$ & $32 \%$ \\
\hline Aureobasidium pullulans & $6.05 \pm 0.35 \mathrm{~A}$ & $7.00 \pm 0.03 \mathrm{C}$ & $25 \%$ \\
\hline Candida oleophila & $4.35 \pm 0.01 \mathrm{C}$ & $7.35 \pm 0.03 \mathrm{C}$ & $26 \%$ \\
\hline Hanseniospora uvarum & $3.80 \pm 0.03 \mathrm{C}$ & $9.12 \pm 0.15 \mathrm{D}$ & $32 \%$ \\
\hline Candida zemplina & $5.85 \pm 0.04 \mathrm{~A}$ & $8.13 \pm 0.07 \mathrm{E}$ & $29 \%$ \\
\hline Rhodotorula glutinis & $7.5 \pm 0.11 \mathrm{D}$ & $6.25 \pm 0.13 \mathrm{C}$ & $22 \%$ \\
\hline M. pulcherrima & $8.15 \pm 1.21 \mathrm{D}$ & $8.01 \pm 0.18 \mathrm{E}$ & $28 \%$ \\
\hline Saccahromyces cerevisiae & $\mathrm{ND}$ & $12.7 \pm 0.11 \mathrm{~F}$ & $45 \%$ \\
\hline
\end{tabular}

ND: Not detected

Values represent the average \pm standard deviation of two trials conducted in triplicated. Different letter within columns represent significant differences $(\alpha=0.05)$

Tabla 4. Final fermented must parameters following sequential inoculation into sterilized Carmerrere must.

\begin{tabular}{|l|l|l|l|l|l|}
\hline Inoculum & $\begin{array}{l}\text { Ethanol yield } \\
(\mathbf{g} \text { ethanol/g } \\
\text { sugar) }\end{array}$ & $\begin{array}{l}\text { Consumed } \\
\text { sugar (\%) }\end{array}$ & Ethanol (g/L) & Glycerol (g/L) & $\begin{array}{l}\text { Acetic } \\
(\mathbf{g} / \mathbf{L})\end{array}$ \\
\hline $\begin{array}{l}\text { R. glutinis }+ \\
\text { S. cerevisiae }\end{array}$ & $0.49 \pm 0.05 \mathrm{~A}$ & $98.5 \pm 0.02 \mathrm{~A}$ & $8.00 \pm 0.31 \mathrm{~A}$ & $11.6 \pm 0.15 \mathrm{~A}$ & $1.08 \pm 0.02 \mathrm{~A}$ \\
\hline $\begin{array}{l}\text { M. pulcherrima } \\
\text { S. cerevisiae }\end{array}$ & $0.46 \pm 0.03 \mathrm{~A}$ & $99.3 \pm 0.03 \mathrm{~A}$ & $7.53 \pm 0.22 \mathrm{~B}$ & $9.58 \pm 0.17 \mathrm{~B}$ & $0.11 \pm 0.01 \mathrm{~B}$ \\
\hline $\begin{array}{l}\text { H. } \text { uvarum } \\
\text { S. cerevisiae }\end{array}$ & $0.39 \pm 0.01 \mathrm{~B}$ & $97.4 \pm 0.02 \mathrm{~B}$ & $6.42 \pm 0.15 \mathrm{C}$ & $15.7 \pm 0.00 \mathrm{C}$ & $2.12 \pm 0.12 \mathrm{C}$ \\
\hline $\begin{array}{l}\text { Control } \\
\text { (S.cerevisiae) }\end{array}$ & $0.50 \pm 0.01 \mathrm{~A}$ & $100 \pm 0.01 \mathrm{~A}$ & $14.5 \pm 1.32 \mathrm{D}$ & $6.71 \pm 0.05 \mathrm{D}$ & $0.38 \pm 0.05 \mathrm{D}$ \\
\hline
\end{tabular}

Non-Saccharomyces yeasts were inoculated at time 0 ( $7 \mathrm{log}$ CFU/ml), S. cerevisiae were inoculation after $65 \%$ sugars were consumed $(5 \mathrm{log}$ CFU/mL). Values represent the average \pm standard deviation of two trials conducted in triplicated. Different letter within columns represent significant diffrerences $(\alpha=0.05)$

\subsection{Caracterización química de la fermentación espontánea}

Los cambios en los sustratos y metabolitos (azúcares, etanol, glicerol y ácidos orgánicos) se midieron por HPLC y, como se esperaba, reflejaron el proceso de fermentación (Tabla 2). La concentración de azúcares disminuyó a medida la fermentación prosiguié y después de 14 días de fermentación, los azúcares alcanzaron valores inferiores a $2 \mathrm{~g} / \mathrm{L}$ para los mostos Merlot, Cabernet Sauvignon y Carignan, mientras que Chardonay, Pinot y Syrha mostraron valores finales más altos. No se detectó etanol en el mosto fresco, y después de la fermentación las concentraciones de etanol fueron similares para Cabernet Sauvignon (9.50 g/l), Chardonay (9.82 g/l) y Carignan $(9.92 \mathrm{~g} / \mathrm{l})$. El valor de etanol más bajo se determinó para Syrah $(5.91 \mathrm{~g} / \mathrm{l})$ y el más alto en Pinot $(11.8 \mathrm{~g} / \mathrm{l})$. Se observó poca o ninguna producción de ácidos orgánicos en los mostos fermentados (Tabla 2). Concentraciones similares de ácido láctico fueron detectadas en C. Sauvignon, Chardonay. Carignan y Pinot, mientras que Merlot y Syrah mostraron concentraciones más bajas. Los valores de ácido acético fueron similares entre todos los mostos fermentados y de concentración baja. Por otro lado, las concentraciones de ácido málico disminuyeron hacia el final de la fermentación con grandes cambios en C. Sauvingnon, Chardonnay y Merlot (Tabla 2).

\subsection{Perfiles de fermentación de levaduras aisladas}

Se usó mosto de uva Carmenere esterilizado para caracterizar el perfil de fermentación de la levadura aislada en cultivo único. Los azúcares residuales fueron específicos y diferentes para los diferentes cultivos y oscilaron entre 3 y $8 \%$. Los porcentajes más bajos se determinaron para $T$. delbrueckii y $C$. boidinii, mientras que $M$. pulcherrima mostró el porcentaje más alto (Tabla 3). Por otro lado, el aislado nativo de $S$. cerevisiae consumió todos los azúcares en el mosto y, por lo tanto, tuvo la mayor concentración de etanol $(12.7 \%$ v/v). Se observaron concentraciones de etanol cercanas o inferiores al $7 \% \mathrm{v} / \mathrm{v}$ para $R$. glutinis $(6.25 \% \mathrm{v} / \mathrm{v})$ y $A$. pullulans $(7 \% \mathrm{v} / \mathrm{v})$. Los otros aislados mostraron concentraciones de alcohol superiores al $7 \% \mathrm{v} / \mathrm{v}$, pero inferiores al $9.5 \%$ v/v. La relación teórica entre la utilización de azúcar y la producción de etanol fue cercana o superior al $30 \%$, a excepción de los aislamientos de $R$. glutinis que mostraron un $22 \%$, mientras que el aislado de $S$. cerevisiae mostró una proporción del 46\% (Tabla 3). En base a estos resultados, se seleccionaron tres especies, R. glutinis (productor de etanol bajo), M. pulcherrima (productor de etanol medio) y $H$. uvarum (productor de alto contenido de etanol), para experimentación en inoculaciones secuenciales con $S$. cerevisiae. 


\subsection{Inoculaciones secuenciales con levaduras nativas seleccionadas}

Se seleccionaron tres levaduras nativas no Saccharomyces para la experimentación en inoculaciones secuenciales con el aislado nativo de $S$. cerevisiae. Las levaduras se inocularon primero en Carmenere fresco, y una vez que se consumieron del 60 al $65 \%$ de azúcares, se añadió $S$. cerevisiae a la fermentación (equivalente a 4 a 5 días desde la fermentación inicial). Después de la inoculación con $S$. cerevisiae, los azúcares se consumieron casi por completo (Tabla 4). Se observaron diferencias significativas en la producción de etanol, glicerol y ácido acético. A pesar de estas diferencias, los vinos resultantes mostraron valores que permiten clasificarlos como vinos reducidos en alcohol, con valores de $8.00,7.53$ y $6.42 \%$ v/v para $R$. glutinis, $M$. pulcherrima y $H$. uvarum, respectivamente (Tabla 4). En contraste, el cultivo de $S$. cerevisiae produjo más etanol $(14.5 \% \mathrm{v} / \mathrm{v})$. Las concentraciones más altas de glicerol se obtuvieron con $H$. uvarum $(15.7 \mathrm{~g} / \mathrm{l})$ y $R$. glutinis $(11.6 \mathrm{~g} / \mathrm{l})$ mientras que el cultivo con $S$. cerevisiae produjo el más bajo $(6.71 \mathrm{~g} / 1)$. La producción de ácido acético fue menor, con el valor más alto alcanzado por el cultivo de $H$. uvarum (2.12g/l) (Tabla 4). Nuestros resultados sugieren que los aislamientos estudiados son capaces de producir vinos estables con contenido de alcohol reducido. Sin embargo, para comprender mejor el potencial enológico de estas levaduras, se necesitan más estudios.

\section{Conclusiones}

Las levaduras nativas $R$. glutinis, $M$. pulcherrima y $H$. uvarum aisladas de bayas de uva chilenas, mostraron interesantes perfiles fermentativos y fueron capaces de producir vinos con contenido de etanol reducido cuando se inocularon con $S$. cerevisiae secuencialmente. Sugiriendo que las levaduras no tradicionales podría ser una alternativa para la producción de vinos reducidos en alcohol con contenidos de etanol inferiores al $9 \%$ v/v. Sin embargo, para evaluar mejor las propiedades enológicas de los aislamientos, es necesario realizar análisis de los compuestos volátiles y sensoriales.
Esta investigación fue financiada por el proyecto Fondef IDeA CA12I10248 y el proyecto Fondecyt Regular 1120679.

\section{Referencias}

[1] N.P. Jolly, O.P.H. Augustyn, I.S. Pretorius, South African J. Enol. Viti. 27, 15 (2006)

[2] M. Quirós, V. Rojasa, R. Gonzanela, P. Morales, Int. J. Food Microbiol. 181, 85 (2014)

[3] M. Ciani, P. Morales, F. Comitini, J. Tronchoni, L. Canonico, J.A. Curiel, L. oro, A.J. Rodrigues, R. Gonzales, Frontiers in Microbiol. 7, 642 (2016)

[4] C. Varela, F. Sengler, M. Solomon, C. Curtin, Food Chem. 209, 57 (2016)

[5] L.M. Schmidtke, J.W. Blackman, S.O. Agboola, J. Food Sci. 71, R25 (2012)

[6] N.P. Jolly, C. Varela, I.S. Pretorius, S. Afr. J. Onel. Vitic. 27, 15 (2014)

[7] I.S. Pretorius, Yeast 16, 675 (2000)

[8] A. Contreras, C. Hidalgo, S. Schmidt, P.A. Hanschke, C. Curtin, C. Varela, Int. J. Food Microbiol. 205, 7 (2015)

[9] A. Contreras, C. Curtin, C. Varela, Appl. Microbiol. Biotech. 99, 1885 (2015)

[10] L. Canonico, F. Comitini, L. Oro, M. Ciani, Frontiers in Microbiol. 7, 278 (2016)

[11] M. Tristezza, M. Tufariello, V. Capozzi, G. Spano, G. Mita, F. Grieco, Frontiers in Microbiol. 7, 7 (2016)

[12] L. Lencioni, C. Romani, M. Gobbi, F. Comitini, M. Ciani, P. Domizio, Int. J. Food Microbiol. 243, 36 (2016)

[13] M.A. Amerine, R.E. Kunkee, Annu. Rev. Microbiol. 22, 323 (1968)

[14] M. Ciani, F. Maccarelli, World J. Microbiol. Biotech. 14, 199 (1998)

[15] A. Soden, I.L. Francis, H. Oakey, P.A. Henschke, Australian J. Grape Wine Res. 6 (2000)

[16] P. Iland, P. Grbdin, M. Grinbergs, L. Schmidtke, A. Soden, Microbiologycal Analysis of Grapes and Wine: Techniques and Concepts (Patrick Iland Wine Promotions Pty Ltd. Australia, 2007) 